\title{
Dinitrophenyl Compounds
}

National Cancer Institute

\section{Source}

National Cancer Institute. Dinitrophenyl Compounds. NCI Thesaurus. Code C441.

Nitroaromatic compounds containing two nitrogen groups on a phenyl ring used as

pharmaceuticals, pesticides, explosives, and comprise a group of environmental pollutants. 